\title{
BMJ Open Symptoms of depression and all-cause mortality in farmers, a cohort study: the HUNT study, Norway
}

\author{
Jon Magne Letnes, ${ }^{1}$ Magnhild Oust Torske, ${ }^{2}$ Bjørn Hilt, ${ }^{3,4}$ \\ Johan Håkon Bjørngaard, ${ }^{3,5}$ Steinar Krokstad ${ }^{2,6}$
}

To cite: Letnes JM, Torske MO, Hilt B, et al. Symptoms of depression and all-cause mortality in farmers, a cohort study: the HUNT study, Norway. BMJ Open 2016;6:e010783. doi:10.1136/bmjopen-2015010783

- Prepublication history and additional material is available. To view please visit the journal (http://dx.doi.org/ 10.1136/bmjopen-2015010783).

Received 8 December 2015 Revised 23 March 2016 Accepted 6 April 2016

CrossMark

For numbered affiliations see end of article.

Correspondence to Jon Magne Letnes; jonmagl@stud.ntnu.no

\section{ABSTRACT}

Objectives: To explore all-cause mortality and the association between symptoms of depression and allcause mortality in farmers compared with other occupational groups, using a prospective cohort design.

Methods: We included adult participants with a known occupation from the second wave of the NordTrøndelag Health Study (Helseundersøkelsen i NordTrøndelag 2 (HUNT2) 1995-1997), Norway. Complete information on emigration and death from all causes was obtained from the National Registries. We used the depression subscale of the Hospital Anxiety and Depression Scale (HADS) to measure symptoms of depression. We compared farmers to 4 other occupational groups. Our baseline study population comprised 32618 participants. Statistical analyses were performed using the Cox proportional hazards models.

Results: The estimated mortality risk in farmers was lower than in all other occupations combined, with a sex and age-adjusted $\mathrm{HR}(0.91,95 \% \mathrm{Cl} 0.82$ to 1.00$)$. However, farmers had an $11 \%$ increased age-adjusted and sex-adjusted mortality risk compared with the highest ranked socioeconomic group (HR 1.11, 95\% $\mathrm{Cl} 0.98$ to 1.25). In farmers, symptoms of depression were associated with a $13 \%$ increase in sex-adjusted and age-adjusted mortality risk (HR $1.13,95 \% \mathrm{Cl} 0.88$ to 1.45). Compared with other occupations this was the lowest HR, also after adjusting for education, marital status, long-lasting limiting somatic illness and lifestyle factors (HR $1.08,95 \% \mathrm{Cl} 0.84$ to 1.39 ).

Conclusions: Farmers had lower all-cause mortality compared with the other occupational groups combined. Symptoms of depression were associated with an increased mortality risk in farmers, but the risk increase was smaller compared with the other occupational groups.

\section{INTRODUCTION}

Several studies have suggested that farmers have better health and lower mortality from, for example, cardiovascular disease and cancer than other occupational groups. A large multinational European study including

\section{Strengths and limitations of this study}

- We used data from a large total population-based cohort in a Norwegian county.

- Outcome ascertainment was based on the National Registry Data with complete follow-up data, and the follow-up time was adequate.

- Information on symptoms of depression, occupational status and other variables was gathered by self-reported answers, which results in some risk of information bias.

- Despite the size of our study population, the power was limited when investigating the association between symptoms of depression and mortality owing to the low number of participants in some of the occupational groups.

We did not have data on cause-specific mortality.

14 countries found that farmers in general had a low mortality rate in the majority of the included countries, even though farmers and self-employed workers were analysed together. ${ }^{1}$ Lower overall mortality for farmers has also been shown in studies from Sweden, ${ }^{2}{ }^{3}$ France $^{4}$ and the USA. ${ }^{5}{ }^{6}$ The mortality in Norwegian farmers was lower than in the average population from 1960 to 2000 , although the difference in mortality rates decreased over the time period. ${ }^{7}$ This lower mortality rate may, at least in part, be due to lifestyle factors such as lower rates of smoking, low intake of alcohol and regular physical activity. ${ }^{2-4}{ }^{6}$ In some studies, however, it has been argued against this possible healthier lifestyle. ${ }^{8}$ Less pronounced social inequality in rural farming communities could reduce psychological stress, which poses another possible salutogenic factor.

Although farmers appear to have lower allcause mortality rates than the average population, several studies have shown that they suffer higher mortality from accidents, ${ }^{5} 9$ specific cancer types ${ }^{5} 9$ and suicide. ${ }^{7}{ }^{10}$ The higher suicide rate among farmers can be 
perceived as a marker for mental health challenges in this industry, as well as higher access to typical suicide means as, for example, fire arms. ${ }^{11}$ Several Norwegian studies, ${ }^{12} 13$ as well as studies from other countries, ${ }^{8} 14$ have reported higher prevalence of depression in farmers compared with other occupational groups, although a few studies also report the contrary. ${ }^{2} 15$ There is a well-established link between depression and mortality. ${ }^{16}{ }^{17}$ The high rate of suicides among farmers indicates that depression in this occupational group could be particularly threatening in regard to mortality risk. The high prevalence of depression in farmers emphasises the necessity for further investigating this association with new data.

Higher levels of mental health problems in agriculture might also be linked to contextual factors. Agriculture in Norway, as in many other developed countries, has undergone major structural changes, including decreasing number of farmers and increasing economical investment per farmer, ${ }^{18}$ changes in technology, globalisation and the political legitimacy of the farming occupation. Such changes may contribute to significantly increase psychosocial stress for those involved. The socioeconomic position (SEP) of farmers may also have been negatively affected along with the changes in premises for farmers. Therefore, one could expect an increase in mental health problems in farmers, and a mortality rate approaching the level of the general population.

\section{Aims and research questions}

We raised the following research questions: (1) What is the all-cause mortality in farmers compared with the general working population and to other occupational groups? (2) Are symptoms of depression associated with an increased risk of all-cause mortality in farmers, and how does this risk compare to other occupational groups?

\section{MATERIALS AND METHODS}

Study population and background

The Helseundersøkelsen i Nord-Trøndelag (HUNT) study

The Nord-Trøndelag Health study (HUNT) is a large population-based study over three decades: HUNT1 (1984-1986), HUNT2 (1995-1997) and HUNT3 (20062008). ${ }^{19}$ In all, over 120000 participants attended the three surveys. Nord-Trøndelag is placed in the middle of Norway, and is said to have the geographical characteristics of a 'miniature Norway', comprising coastline, fjords, mountains and widespread agricultural areas; indicating the importance of the farming profession in the area. Roughly 135000 residents (October 2013) are settled in small towns and rural areas, distributed over 23 municipalities. Compared with Norway as a whole, Nord-Trøndelag County has similar rates of morbidity, specific and all-cause mortality, as well as similar sources of income, types of industry and age distribution. ${ }^{20}$
Average income, prevalence of higher education and smoking prevalence are somewhat lower than the national average. ${ }^{20}$

\section{Data collection and selection of study participants}

We used HUNT2 as the baseline for our analyses in this prospective cohort study. All residents of Nord-Trøndelag aged 20 and above $(n=92936)$ were invited to participate. ${ }^{20}$ An invitation letter containing a four-page questionnaire (questionnaire 1, Q1) was sent by mail to the respondents. This questionnaire was completed prior to attendance at the screening site. A second questionnaire $(\mathrm{Q} 2)$ was handed out at the screening site and was completed and returned by mail free of cost for the participant. Of the invited residents, $65232(70.2 \%)$ participated. We excluded those without an identifiable occupation and those with missing data on other study variables, yielding a basal study population of 32618 . The selection process is further illustrated in figure 1. Of the aforementioned basal study population, 190 participants had missing the Hospital Anxiety and Depression Scale (HADS) values, and were thus omitted from the analyses that demanded these data. Information on occupation was asked in questionnaire 2 , which had to be returned by mail by the participants, thereby resulting in a lower response rate.

\section{Mortality}

The Norwegian National Registry, underlying the Norwegian Tax Administration, gathers mortality data continuously. Death certificates are issued by medical doctors and sent to the district court, which notifies the National Registry. Linkage of data between the HUNT database and the National Registries is possible as all Norwegian citizens have their own unique 11-digit personal identification number. Data on emigration and death can hence be considered complete. We did not have data on cause-specific mortality. The average life expectancy in Norway was 74.8 years for men and 80.8 years for women in 1995 , and 80.0 for men and 84.1 for women in 2014 (data from Statistics Norway which gathers data from the National Registry).

\section{Occupation}

The classification of occupation in HUNT2 was based on a Norwegian occupational standard which is similar to the social class scheme by Erikson, Goldthorpe and Portocarero (EGP), ${ }^{21}$ and its use in employing a socioeconomic rank in health has been investigated in a previous study. ${ }^{22}$ The HUNT2 occupational categories were (1) 'management position in public or private enterprise'; (2) 'self-employed professional (dentist, lawyer, etc)'; (3) 'lower professional occupation (nurse, technician, teacher, etc)'; (4) 'non-professional occupation (shop, office, public service)'; (5) 'farmer or forest owner'; (6) 'self-employed businessman'; (7) 'skilled worker, artisan, foreman'; (8) 'driver, chauffeur'; (9) 'fisherman' and (10) 'semi-skilled, unskilled worker'. 


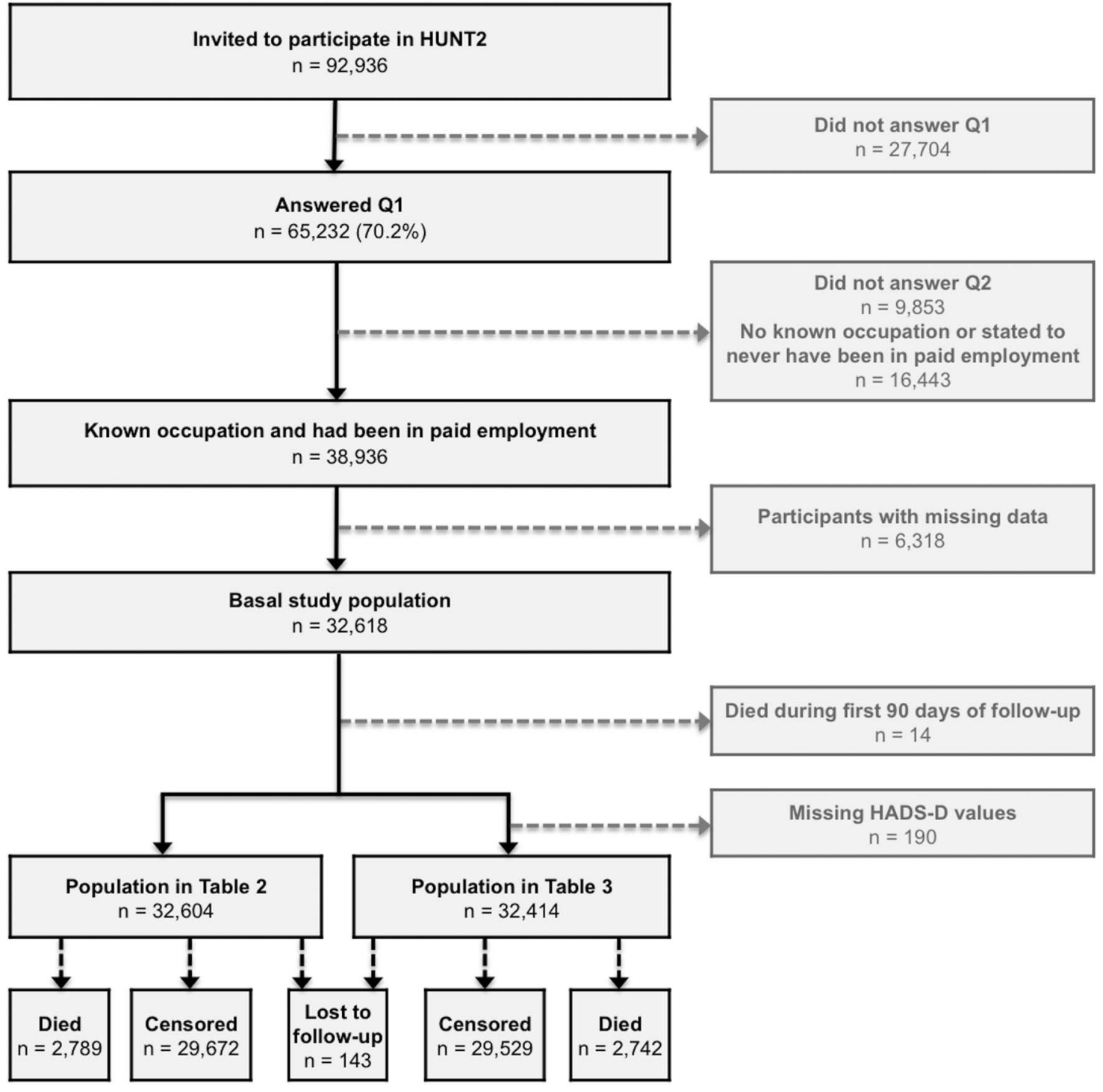

Figure 1 Selection of study population. HUNT2, second wave of the Nord-Trøndelag Health Study; Q1, questionnaire 1; Q2, questionnaire 2; HADS-D, Hospital Anxiety and Depression Scale, depression item.

The occupational categories from HUNT2 were placed in a simplified version of the EGP scheme, consisting of (I) professionals (1-3), (II) routine non-manual workers (4), (III) farmers (5), (IV) self-employed businessmen (6), (V) manual workers (7-10). These broader categories were employed instead of the original EGP scheme owing to the low numbers of events (deaths) in some of the original EGP categories, making the statistical analyses difficult without making such an adjustment. A substantial proportion of the respondents $(6.7 \%$ of the all other occupations (AOOs) group vs $23.5 \%$ of those coded as farmers) reported having two or more professions. We assumed that respondents with several occupations would experience the main influence on health from the occupation with the highest SEP. Study participants with two or more occupations were thus recoded to the occupation with the highest SEP in accordance with the simplified EGP scheme. Farming was the highest SEP occupation among $83 \%$ of the participants who reported farming as at least one of their occupations. Both currently employed and unemployed participants were included in the analyses, as the questionnaire (Q2) instructed participants to report both current and former occupations.

\section{Variables in the analyses}

Symptoms of depression: Questionnaire 1 included a Norwegian translation of the $\mathrm{HADS}^{23}$ which assesses psychological symptoms of anxiety (HADS-A) and depression (HADS-D) during the preceding week. Each subscale (HADS-A/HADS-D) comprises seven items. A minimum of five of the seven HADS-D questions had to be answered for the score to be valid. Missing values were replaced by multiplying the total score by $7 / 5$ or $7 / 6$, when there were two or one missing responses, respectively. Each question scored 0-3 points, with the highest score reflecting the maximal symptom pressure per question, making the maximum symptom pressure 
score 21. A cut-off score of $\geq 8$ has been found to be the most reliable (both sensitivity and specificity of 0.8$){ }^{24}$ We used $\geq 8$ as the cut-off in our analyses, and the presence of HADS caseness of depression will be referred to as 'symptoms of depression'. A separate study has verified that the internal consistency of the HADS scheme in the HUNT2 study is satisfactory. ${ }^{25}$

Somatic long-lasting, limiting illness: Participants were asked to assess if they had a long-lasting (minimum 1 year) illness that affected their daily functioning. Those who answered 'yes' were subsequently asked if they had a somatic illness, and to rate to what degree it limited their daily functioning on a scale from one to three. We dichotomised somatic long-lasting, limiting illness to 'present'/ 'not present' in our analyses.

Educational level: Information about educational level on a five-level scale was obtained from the questionnaire.

Smoking status: Current smoking status was categorised to 'yes/no', and we used this dichotomised variable in our analyses. Participants answering 'yes' were asked to estimate the number of cigarettes smoked per day.

Alcohol: A Norwegian version of the widely used CAGE screening instrument (Cut down, Annoyed, Guilt, Eye-opener) was utilised for detecting possible alcohol abuse. Comprising four 'yes/no' questions, it is widely used in clinical settings, but it has also been validated for population-based studies. ${ }^{26}$ A cut-off of $\geq 2$ positive answers has been argued to be optimal for detecting possible alcohol abuse, ${ }^{27}$ and we used this cut-off in our study.

Marital status: Information about marital status was given on a nine-subset scale from the National Registry to the HUNT database. In our analyses, it was simplified to four categories: 'unmarried', 'married/registered partner', 'widowed' and 'divorced/separated'.

Physically demanding work: Participants were asked to grade how often they were physically worn out after a day's work on a four-subset scale. 'Nearly always' and 'quite often' were coded as physically demanding work, while 'seldom' and 'never or almost never' were coded as not having physically demanding work.

\section{Statistical analysis}

\section{Follow-up and end points}

The start of follow-up was defined as the date the participants completed the first questionnaire, being between August 1995 and June 1997. Participants were followed until date of death by any cause, date of emigration, or 15 March 2014, whichever came first. To reduce reverse causality, we eliminated the first 90 days of follow-up after participation in HUNT2. During these 90 days, 14 participants were censored and hence not included in the analyses.

\section{Survival analysis}

The Cox proportional hazards model, with the time since participation in HUNT as the time axis, was used to calculate mortality HRs of the occupational groups, using the 'professionals' group as reference (the highest EGP social class category). Owing to the low numbers of women in some of the occupational groups, analyses were not stratified by sex, but rather adjusted for. The first model was adjusted for confounding from age as a continuous variable and sex. The second model also included adjustment for educational level and marital status. Model 3 was adjusted for somatic long-lasting, limiting illness as well, and in the fourth model we also adjusted for lifestyle factors (body mass index (BMI), smoking status and possible alcohol abuse). To test the possible association between depression and mortality, four more models were set up in which the five occupational classes were stratified and analysed, adjusted as for the previous mentioned models. We tested for statistical interaction between the symptoms of depression and occupational variables by comparing models with and without statistical interaction, using a likelihood ratio test.

The Mann-Whitney $\mathrm{U}$ test and the $\chi^{2}$ test were performed to test statistical significance between farmers and AOOs) regarding general characteristics (table 1).

The proportional hazard assumption was tested by investigating $\log -\log$ curves. Precision was evaluated with 95\% CIs. The statistical analyses were completed using SPSS V.21.

\section{RESULTS}

\section{General characteristics}

The general characteristics of the study participants are presented in table 1 . The majority of farmers were men (73\%), fewer were current smokers than in the 'AOOs' group, and farmers reported lower levels of probable alcohol problems and more physically demanding work. HADS caseness of depression in farmers was the highest of all the occupational groups, and the educational level was, as expected, among the lowest. Detailed information on the scores for the seven individual HADS depression items in the respective occupational categories is presented in online supplementary table S1. The farmers also had the oldest population, with an average of 3.7 years older than AOOs combined. The farmers and the AOO group were statistically significantly different for all variables, except for the number of cigarettes smoked per day.

\section{Mortality based on occupational groups}

Of the 32618 participants in the baseline study population, 2789 died, and 143 were lost to follow-up due to emigration. The average follow-up time was 17.1 years. The total mortality incidence rate in our study population was 500.6 per 100000 person years, and 675.3 per 100000 person years in farmers.

Table 2 presents the HR for dying in the different occupational categories. In model 1 , adjusted for age and sex, farmers showed a HR for dying of 1.11 (95\% CI 
Table 1 Overview of general characteristics of farmers compared with other occupational categories and AOOs combined

\begin{tabular}{|c|c|c|c|c|c|c|}
\hline & Farmers & AOO & Professionals & $\begin{array}{l}\text { Routine } \\
\text { non-manual } \\
\text { workers }\end{array}$ & $\begin{array}{l}\text { Self-employed } \\
\text { workers }\end{array}$ & $\begin{array}{l}\text { Manual } \\
\text { workers }\end{array}$ \\
\hline n (=32 618) & 3962 & 28656 & 9236 & 7170 & 1592 & 10658 \\
\hline Sex $(\%$, male $)$ & 73.0 & 48.5 & 49.5 & 19.1 & 62.1 & 65.4 \\
\hline Age (years, mean) & 47.4 & 43.7 & 44.4 & 43.5 & 46.0 & 42.8 \\
\hline Caseness HADS-D (\%) & 13.1 & 8.4 & 7.1 & 8.3 & 9.3 & 9.4 \\
\hline HADS-D score (mean) & 3.9 & 3.1 & 2.9 & 3.1 & 3.4 & 3.3 \\
\hline $\begin{array}{l}\text { Somatic long-lasting limiting } \\
\text { illness (\%) }\end{array}$ & 14.2 & 11.1 & 9.1 & 11.1 & 12.5 & 12.6 \\
\hline \multicolumn{7}{|l|}{ Educational level (\%) } \\
\hline Primary school & 37.3 & 24.0 & 4.9 & 26.0 & 32.1 & 38.1 \\
\hline Some secondary school & 48.7 & 38.2 & 19.3 & 44.5 & 46.4 & 49.2 \\
\hline $\begin{array}{l}\text { Completed secondary } \\
\text { education }\end{array}$ & 8.8 & 10.7 & 6.6 & 18.7 & 10.2 & 9.1 \\
\hline University/college $<4$ years & 4.4 & 16.3 & 37.9 & 9.5 & 8.9 & 3.2 \\
\hline University/college >4 years & 0.8 & 10.8 & 31.3 & 1.4 & 2.4 & 0.5 \\
\hline Married/registered partner (\%) & 72.8 & 62.7 & 69.9 & 62.8 & 69.0 & 55.5 \\
\hline Smokers (\%) & 25.2 & 32.6 & 23.0 & 35.3 & 35.0 & 38.8 \\
\hline Cigarettes per day (mean) & 11.8 & 11.7 & 11.7 & 10.6 & 13.3 & 12.1 \\
\hline Probable alcohol problem (\%) & 7.3 & 9.2 & 8.3 & 5.6 & 9.8 & 12.3 \\
\hline $\mathrm{BMI}\left(\mathrm{kg} / \mathrm{m}^{2}\right.$, mean $)$ & 26.6 & 26.0 & 25.8 & 25.7 & 26.6 & 26.3 \\
\hline Physically demanding work (\%) & 71.7 & 39.0 & 24.7 & 31.3 & 46.3 & 56.6 \\
\hline
\end{tabular}

The HUNT study (HUNT2 1995-1997), Norway.

AOO, all other occupation; BMI, body mass index; HADS-D, Hospital Anxiety and Depression Scale, depression item; HUNT2, second wave of the Nord-Trøndelag Health Study.

0.98 to 1.25$)$ compared with professionals. In model 4, adjusted for all mentioned variables, the HR was attenuated to 0.96 (95\% CI 0.83 to 1.11$)$, the lowest estimated HR. Compared with AOO, the mortality risk of farmers was lower adjusted for age and sex in model 1 (borderline statistically significant HR $0.91,95 \%$ CI 0.82 to 1.00). When adjusting for educational and marital status in model 2, the HR for farmers was reduced from 0.91 to 0.86 compared with AOO, and subanalysis showed that educational status explained this reduction alone. In model 4, adjusted for all mentioned variables, farmers had a HR of 0.92 (95\% CI 0.83 to 1.02$)$.

\section{Symptoms of depression and all-cause mortality}

The associations between caseness of depression and allcause mortality in the occupational groups are presented in table 3 . The analyses are stratified by occupational group, and the HRs represents the increased risk of death for workers with symptoms of depression, compared with the workers in the same occupational group without such symptoms of depression (reference category). Farmers with symptoms of depression had a $13 \%$ increased mortality risk (model 1: age-adjusted and sexadjusted HR of 1.13 , 95\% CI 0.88 to 1.45 ) compared with farmers with no symptoms of depression. The estimates were attenuated in the subsequent models, and the same main patterns were seen there, except for the self-employed workers group, which showed a higher HR in models 3 and 4. There was no evidence of statistical interaction between occupational category and depression or between occupational category and other covariates.

\section{Sensitivity analyses}

We performed analyses starting the follow-up 1 and 2 years after the baseline without substantial effects on our estimates.

Sensitivity analyses on the association between HADS-D scores as a continuous variable and mortality were also performed, with similar results regarding farmers (see online supplementary table S2).

To assess whether our hierarchical method of assigning occupation to study participants with several occupations affected our results, we performed sensitivity analyses on the study participants who answered having only one occupation $(n=29760)$. The all-cause mortality of farmers compared with AOO was virtually unchanged (HR 0.90, 95\% CI 0.80 to 1.00 , adjusted as for model 1 ). Analyses on all-cause mortality according to the baseline symptoms of depression were also performed on this selection $(n=29589)$ with only minor changes to the estimates (farmers' HR $1.10,95 \%$ CI 0.83 to 1.45 and AOO HR 1.40, 95\% CI 1.24 to 1.58; adjusted as for model 1). We also analysed all participants who reported farming as an occupation (including those coded with a higher SEP occupation (higher SEP farmers)) together for the association of depression and mortality $(n=4708)$. This analysis gave a slightly higher HR (model 1: HR of farmers $1.19,95 \%$ CI 0.95 to 1.51 ; model 4 : HR of farmers $1.14,95 \%$ CI 0.90 to 1.44 ). Subgroup analysis 
Table 2 HR with $95 \%$ Cls for all-cause mortality according to baseline occupational groups

\begin{tabular}{|c|c|c|c|c|c|c|c|}
\hline & $\mathbf{N}$ & Events (n) & $\begin{array}{l}\text { Mortality incidence } \\
\text { rate per } 10^{5} \text { person years }\end{array}$ & $\begin{array}{l}\text { Model } 1 \\
\text { HR }(95 \% \mathrm{Cl})\end{array}$ & $\begin{array}{l}\text { Model } 2 \\
\text { HR }(95 \% \mathrm{Cl})\end{array}$ & $\begin{array}{l}\text { Model } 3 \\
\text { HR }(95 \% \mathrm{CI})\end{array}$ & $\begin{array}{l}\text { Model } 4 \\
\text { HR }(95 \% \mathrm{CI})\end{array}$ \\
\hline Professionals & 9235 & 626 & 395.0 & 1 & 1 & 1 & 1 \\
\hline Routine non-manual workers & 7167 & 487 & 395.2 & 1.19 (1.05 to 1.35$)$ & 1.01 (0.88 to 1.17$)$ & $1.00(0.87$ to 1.16$)$ & $0.98(0.85$ to 1.14$)$ \\
\hline Farmers & 3958 & 454 & 675.3 & $1.11(0.98$ to 1.25$)$ & $0.93(0.81$ to 1.08$)$ & $0.93(0.80$ to 1.07$)$ & $0.96(0.83$ to 1.11$)$ \\
\hline Self-employed workers & 1591 & 181 & 674.1 & $1.32(1.12$ to 1.56$)$ & 1.15 (0.96 to 1.38$)$ & 1.15 (0.96 to 1.38$)$ & 1.10 (0.92 to 1.32$)$ \\
\hline Manual workers & 10653 & 1041 & 574.1 & $1.38(1.25$ to 1.53$)$ & $1.13(1.00$ to 1.29$)$ & $1.12(0.98$ to 1.27$)$ & $1.08(0.95$ to 1.23$)$ \\
\hline All other occupations & 28646 & 2335 & 476.7 & 1 & 1 & 1 & 1 \\
\hline Farmers & 3958 & 454 & 675.3 & $0.91(0.82$ to 1.00 & $0.86(0.78$ to 0.95$)$ & $0.86(0.78$ to 0.95$)$ & $0.92(0.83$ to 1.02$)$ \\
\hline
\end{tabular}

Table 3 HR with $95 \%$ Cls for all-cause mortality according to baseline depression symptoms stratified by occupational group

\begin{tabular}{|c|c|c|c|c|c|c|c|}
\hline & $\mathbf{N}$ & Events (n) & $\begin{array}{l}\text { Events with } \\
\text { depression (n) }\end{array}$ & $\begin{array}{l}\text { Model } 1 \\
\text { HR (95\% Cl) }\end{array}$ & $\begin{array}{l}\text { Model } 2 \\
\text { HR }(95 \% \mathrm{CI})\end{array}$ & $\begin{array}{l}\text { Model } 3 \\
\text { HR }(95 \% \mathrm{Cl})\end{array}$ & $\begin{array}{l}\text { Model } 4 \\
\text { HR }(95 \% \mathrm{CI})\end{array}$ \\
\hline Professionals & 9200 & 620 & 69 & $1.34(1.04$ to 1.71$)$ & 1.30 (1.02 to 1.67$)$ & 1.19 (0.93 to 1.53$)$ & 1.14 (0.89 to 1.47$)$ \\
\hline Routine non-manual workers & 7136 & 479 & 66 & 1.27 (0.98 to 1.65$)$ & $1.24(0.95$ to 1.61$)$ & $1.18(0.91$ to 1.54$)$ & $1.13(0.87$ to 1.47$)$ \\
\hline Farmers & 3922 & 440 & 71 & $1.13(0.88$ to 1.45$)$ & $1.12(0.87$ to 1.44$)$ & 1.07 (0.83 to 1.37$)$ & 1.08 (0.84 to 1.39$)$ \\
\hline Self-employed workers & 1578 & 176 & 21 & $1.25(0.80$ to 1.96$)$ & $1.25(0.80$ to 1.96$)$ & $1.27(0.81$ to 2.00$)$ & $1.30(0.82$ to 2.04$)$ \\
\hline Manual workers & 10578 & 1027 & 162 & $1.42(1.20$ to 1.68$)$ & 1.38 (1.17 to 1.63$)$ & 1.34 (1.13 to 1.58$)$ & 1.27 (1.08 to 1.51$)$ \\
\hline All other occupations & 28492 & 2302 & 318 & $1.38(1.22$ to 1.55$)$ & 1.33 (1.18 to 1.49$)$ & $1.27(1.13$ to 1.43$)$ & $1.21(1.08$ to 1.36$)$ \\
\hline
\end{tabular}

Model 1: adjusted for age as a continuous variable and sex.

Model 2: model 1+educational level and marital status.

Model 3: model 2+long-lasting, limiting somatic illness.

Model 4: model 3+lifestyle factors (body mass index, smoking status and possible alcohol abuse). 
on the higher SEP farmers $(\mathrm{n}=786)$ showed a higher HR for death when present caseness of depression (model 1: HR 1.92, 95\% CI 1.01 to 3.68; model 4: HR $1.92,95 \%$ CI 0.96 to 3.82 ). This subgroup further had a caseness of depression prevalence of $9.6 \%$, which is somewhat lower than the farmer's category depicted in tables 2 and 3. The original farmers occupational group had a HR of death of 1.14 (95\% CI 0.86 to 1.51, adjusted as for model 1) compared with the higher SEP farmers; which is in line with the findings for farmers compared with the higher SEP occupational categories as shown in table 2.

\section{DISCUSSION}

Our results suggest that the all-cause mortality rate in farmers was the lowest compared with AOO. However, farmers had an 11\% increased age-adjusted and sexadjusted mortality risk compared with the highest ranked socioeconomic group. As in the other occupational groups, having symptoms of depression was associated with increased mortality risk in farmers, but the increased risk for farmers was relatively low.

\section{Comparison with other studies}

Several studies have found that the mortality of farmers is low compared with other occupations, and our findings from a large, whole population survey in Norway support the majority of the existing literature. ${ }^{1-7}$ Studies from Sweden ${ }^{2} 3$ have shown that the lower mortality in farmers is partly explained by the urban-rural effect, meaning that some of the difference could be explained by an urban-rural gradient in health. However, there are no major cities in Nord-Trøndelag, and the county as a whole is best described as rural, making a possible urban-rural gradient in health less likely as an explanation for the low mortality rate among farmers in our study population.

Selection bias, in form of the healthy worker effect, is a possible explanation of the low mortality rate. It is possible that only the healthiest farmers stay in such a physically and mentally demanding occupation, resulting in a healthy farming population. A French study conducted on a semipublic and private sector population showed that men with high transition rates between different occupational groups had higher mortality rates. ${ }^{28}$ Anticipation of job loss has also been shown to negatively affect health status, even before the event has taken place. $^{29}$ Norwegian agriculture has experienced extensive changes during the last decades, as in most developed countries, ${ }^{18}$ which have led to large numbers of farmers leaving the occupation, while the size of the average farm grows bigger. In Norway, the number of farming businesses has declined $36 \%$ from 1999 to 2011, and the average acreage per farm has increased by $49 \%$ over the same period. ${ }^{30}$ It is possible that only the healthiest farmers are able to cope with such changes.
Our results indicate that lifestyle factors such as the low prevalence of possible alcohol abuse and smoking may contribute to the low mortality of farmers. This is in line with findings from an American study which recently investigated the contribution of behavioural factors on mortality in a socioeconomic perspective. Cigarette smoking, physical activity, alcohol consumption and BMI could explain $40-50 \%$ of the difference in mortality when SEP was measured by education, and 24$39 \%$ when measured by income. ${ }^{31}$ Such lifestyle factors may compensate for possible harmful effects of workrelated stressors in agriculture. Farming is known for several potentially harmful work-related factors such as long and unfavourable working hours, low income and exposure to ergonomic risk factors, ${ }^{32}$ as well as the possibly stressful impact of frequently changing legislations and regulations. ${ }^{33}$

\section{Symptoms of depression and mortality}

Depression, both clinical and subclinical, has been associated with increased mortality, ${ }^{16}{ }^{17}$ although it seems that the association of depression and mortality in an occupational or socioeconomic setting is not very well explored. Studies from England have indicated that low socioeconomic status and psychological distress might have a multiplicative effect on all-cause mortality, ${ }^{34}$ and mortality from coronary heart disease and stroke. ${ }^{35}$ Our estimates indicate that the association between depression and mortality is present in all occupational groups, although we only found this association to be statistically significant in the professionals and manual worker groups. Our analyses indicated that some of the association between symptoms of depression and mortality was due to differences in somatic illness at baseline, and the effect was comparable in magnitude between the occupational classes except for the self-employed workers category. Lifestyle factors explained some of the mortality difference between participants with and without caseness of depression, although not in farmers. Lifestyle factors such as lower rates of physical activity, changes towards an unhealthy diet, increased rates of smoking and higher alcohol consumption have been proposed as mediating factors between depression and death in earlier studies. ${ }^{36}$ Educational level and marital status explained some of this difference in all occupations, except in self-employed workers.

A Finnish study found that the relative mortality risk from alcohol-related causes of death among depressed individuals was larger in the groups of higher socioeconomic status. ${ }^{37}$ On the other hand, another Finnish study with government employees only ${ }^{38}$ found a higher risk of suicide and alcohol-related deaths among people with lower SEP when measured at educational and occupational level-and the lower SEP groups also showed higher all-cause mortality. They also found that the lower SEP groups used less antidepressant medications, suggesting several mechanisms for bias in defining the caseness of depression. Yet another Finnish study 
indicated small differences between higher and lower SEP groups in risk of disability retirement from depression and unnatural and alcohol-related mortality. ${ }^{39}$ All in all, the available research on the association between depression and mortality in a socioeconomic perspective is rather scarce and inconclusive.

\section{Strengths and limitations}

To our knowledge, our study is the first to investigate the association between depression and mortality in farmers. The presented results were based on a large populationbased prospective cohort with a relatively high ${ }^{20}$ response rate for a large-scale population survey. The risk of non-response bias should however be acknowledged. We used high-quality National Registry Data to measure end points. Loss to follow-up was due to emigration only and was very low $(0.4 \%)$. Despite the size of HUNT2, our study has limited power when investigating the association between caseness of depression and mortality, owing to the low number of participants in each of the occupational groups with caseness of depression who subsequently died. The employment of selfreported data to assess several baseline variables in the analyses is considered a weakness. For example, data on pre-existing somatic long-lasting, limiting illness was gathered by self-reported answers. Using objective, clinical measures of somatic illness probably would have reduced the risk of misclassification, but we did not have such data available. Several participants reported multiple occupations, and we picked the occupation with the highest SEP in the EGP scheme. An alternative and probably better approach might have been to classify study participants based on their main occupation, but information on the main occupation was not available to us. This may have led to a biased classification of workers as farmers, which would subsequently affect our estimates. This is especially relevant since one out of five farmers in our population stated that they had more than one occupation. However, sensitivity analyses on participants reporting only one occupation gave similar results. The results for higher SEP farmers (farmers classified with a higher SEP occupation) were more similar to the higher SEP categories, which might indicate that the choice to place participants with multiple occupations in the category with the highest SEP could have been a legitimate decision.

Using the HADS as a case finder for depression has been validated, ${ }^{24}$ but it is a screening tool for symptoms of depression, and not a diagnostic tool. Symptoms of depression measured at baseline could have been triggered by a variety of stressors, and may, therefore, not necessarily reflect a long-lasting depression. The HADS only asks questions on symptoms of depression during the last week, which is a rather short time span. An actual episode of depression could also be very limited in time, and thus not have any impact on health or subsequent mortality. Although there is a possible risk of information bias regarding caseness of depression classification, given the prospective study design, misclassification of depression is likely to be nondifferential. Hence, given a dichotomous classification of symptoms of depression, we would expect the results to be reduced in the case of non-differential misclassification. We dichotomised the depression subscale of the HADS, and a categorical approach has been shown to decrease statistical power and increase the risk of erroneously interpreting results as 'no association' (type II error) compared with dimensional models. ${ }^{40}$ However, categorisation into 'healthy' or 'ill' is more clinically applicable, and often easier to interpret and communicate. Moreover, sensitivity analyses with HADS depression scores measured at continuous level gave similar results regarding farmers.

Although our results cannot be directly generalised to all countries, they should be of interest for countries with similar socioeconomic environment and agricultural development such as the majority of the Scandinavian, Central and Western European and North American countries. ${ }^{18}$

\section{CONCLUSIONS AND FINAL COMIMENTS}

Farmers had lower all-cause mortality compared with other occupational groups combined, but an $11 \%$ increased age-adjusted and sex-adjusted mortality risk compared with the highest ranked socioeconomic group. A healthy lifestyle despite a lower level of education among farmers is probably of significance regarding these findings. Symptoms of depression were associated with an increased mortality risk in farmers, but the risk increase was smaller than in other occupational groups. This is of importance when we keep in mind the well-established evidence for a high level of depression in this occupational group. Further investigations, like disability-adjusted life years or measures of lost economic productivity or social costs related to depression, should be performed to estimate the public health burden of the situation for farmers in Norway and elsewhere.

\section{Author affiliations}

${ }^{1}$ Norwegian University of Science and Technology, NTNU, Trondheim, Norway ${ }^{2}$ HUNT Research Centre, Department of Public Health and General Practice, Faculty of Medicine, the Norwegian University of Science and Technology (NTNU), Levanger, Norway

${ }^{3}$ Faculty of Medicine, Department of Public Health and General Practice, The Norwegian University of Science and Technology, Trondheim, Norway ${ }^{4}$ Department of Occupational Medicine, St. Olavs Hospital, Trondheim University Hospital, Trondheim, Norway

${ }^{5}$ Forensic Department, Research Centre Bröset St. Olav's University Hospital Trondheim, Trondheim, Norway

${ }^{6}$ Levanger Hospital, Nord-Trøndelag Health Trust, Levanger, Norway

Twitter Follow Steinar Krokstad at @steinak

Acknowledgements The Nord-Trøndelag Health Study (the HUNT study) is a collaboration between HUNT Research Centre (Faculty of Medicine, Norwegian University of Science and Technology NTNU), Nord-Trøndelag County Council, Central Norway Health Authority, and the Norwegian Institute of Public Health. 
Contributors The manuscript has been contributed to in such a manner that all five authors have met requirements for authorship. The main contributions are as follows: (1) JML was involved in study design and idea, statistical analysis, main author and guarantor. (2) MOT was involved in study design and idea, statistical analysis, contributing author. (3) BH is the contributing author. (4) JHB was involved in statistics, and is the contributing author. (5) SK was involved in study design and idea, and is the contributing author.

Funding The project was funded by the Norwegian Research Council and the Norwegian University of Science and Technology (NTNU).

Competing interests None declared.

Patient consent Obtained.

Ethics approval The Regional Committee for Medical and Health Research Ethics (REK) approved the study, and the National Data Inspectorate approved the HUNT study.

Provenance and peer review Not commissioned; externally peer reviewed.

Data sharing statement Data from the HUNT study will, when reasonably requested, be made available on request to the HUNT Data Access Committee (hunt@medisin.ntnu.no). The HUNT data access information (available here: http://www.ntnu.edu/hunt/data) describes in detail the policy regarding data availability. However, due to ethical restrictions involving patient consent, data cannot be posted publicly.

Open Access This is an Open Access article distributed in accordance with the Creative Commons Attribution Non Commercial (CC BY-NC 4.0) license, which permits others to distribute, remix, adapt, build upon this work noncommercially, and license their derivative works on different terms, provided the original work is properly cited and the use is non-commercial. See: http:// creativecommons.org/licenses/by-nc/4.0/

\section{REFERENCES}

1. Toch-Marquardt M, Menvielle G, Eikemo TA, et al. Occupational class inequalities in all-cause and cause-specific mortality among middle-aged men in 14 European populations during the early 2000s. PLOS ONE 2014; 9:e108072.

2. Stiernstrom EL, Holmberg S, Thelin A, et al. A prospective study of morbidity and mortality rates among farmers and rural and urban nonfarmers. J Clin Epidemiol 2001;54:121-6.

3. Thelin N, Holmberg S, Nettelbladt P, et al. Mortality and morbidity among farmers, nonfarming rural men, and urban referents: a prospective population-based study. Int J Occup Environ Health 2009;15:21-8.

4. Leveque-Morlais N, Tual S, Clin B, et al. The AGRlculture and CANcer (AGRICAN) cohort study: enrollment and causes of death for the 2005-2009 period. Int Arch Occup Environ Health 2014;88:61-73.

5. Waggoner JK, Kullman GJ, Henneberger PK, et al. Mortality in the agricultural health study, 1993-2007. Am J Epidemiol 2011;173:71-83.

6. Armitage TL, Mitchell D, Schenker M. Mortality in the California farmer health study cohort. J Agromedicine 2012;17:288-99.

7. Borgan JK. Yrke og dødelighet 1960-2000 [Occupational mortality 1960-2000]. Statistics Norway, 2009.

8. Demos K, Sazakli E, Jelastopulu E, et al. Does farming have an effect on health status? A comparison study in west Greece. Int J Environ Res Public Health 2013;10:776-92.

9. Rautiainen $\mathrm{RH}$, Reynolds SJ. Mortality and morbidity in agriculture in the United States. J Agric Saf Health 2002;8:259-76.

10. Milner A, Spittal MJ, Pirkis J, et al. Suicide by occupation: systematic review and meta-analysis. Br J Psychiatry 2013;203: 409-16.

11. Booth N, Briscoe M, Powell R. Suicide in the farming community: methods used and contact with health services. Occup Environ Med 2000;57:642-4.

12. Sanne B, Mykletun A, Moen BE, et al. Farmers are at risk for anxiety and depression: the Hordaland Health Study. Occup Med (Lond) 2004;54:92-100.

13. Torske MO, Hilt B, Glasscock D, et al. Anxiety and depression symptoms among farmers: the HUNT Study, Norway. J Agromedicine 2016;21:24-33.
14. Hounsome B, Edwards RT, Hounsome N, et al. Psychological morbidity of farmers and non-farming population: results from a UK survey. Community Ment Health J 2012;48:503-10.

15. Thomas HV, Lewis G, Thomas DR, et al. Mental health of British farmers. Occup Environ Med 2003;60:181-5; discussion 85-6.

16. Mykletun A, Bjerkeset O, Dewey M, et al. Anxiety, depression, and cause-specific mortality: the HUNT study. Psychosom Med 2007;69:323-31.

17. Cuijpers $P$, Vogelzangs $\mathrm{N}$, Twisk J, et al. Differential mortality rates in major and subthreshold depression: meta-analysis of studies that measured both. Br J Psychiatry 2013;202:22-7.

18. FAO. The state of food and agriculture. Food and agriculture organization of The United Nations, 2012.

19. Krokstad S, Langhammer A, Hveem K, et al. Cohort profile: the HUNT Study, Norway. Int J Epidemiol 2013;42:968-77.

20. Holmen J, Midthjell K, Krüger $\varnothing$, et al. The Nord-Trøndelag Health Study 1995-97 (HUNT 2): objectives, contents, methods and participation. Norsk Epidemiol 2003;13:13.

21. Erikson R, Goldthorpe JH, Portocarero L. Intergenerational class mobility in 3 Western European societies-England, France and Sweden. Br J Sociol 1979;30:415-41.

22. Krokstad S, Ringdal K, Westin S. Classifying people by social class in population based health surveys: two methods compared. Norsk Epidemiol 2002;12:19-25.

23. Zigmond AS, Snaith RP. The hospital anxiety and depression scale. Acta Psychiatr Scand 1983;67:361-70.

24. Bjelland I, Dahl AA, Haug TT, et al. The validity of the Hospital Anxiety and Depression Scale. An updated literature review. J Psychosom Res 2002;52:69-77.

25. Mykletun A, Stordal E, Dahl AA. Hospital Anxiety and Depression (HAD) scale: factor structure, item analyses and internal consistency in a large population. Br J Psychiatry 2001;179:540-4.

26. Skogen JC, Overland S, Knudsen AK, et al. Concurrent validity of the CAGE questionnaire. The Nord-Trondelag Health Study. Addict Behav 2011;36:302-7.

27. Smart RG, Adlaf EM, Knoke D. Use of the CAGE scale in a population survey of drinking. J Stud Alcohol 1991;52:593-6.

28. Karimi M, Geoffroy-Perez B, Fouquet A, et al. Socioprofessional trajectories and mortality in France, 1976-2002: a longitudinal follow-up of administrative data. J Epidemiol Community Health 2015;69:339-46.

29. Ferrie JE, Shipley MJ, Marmot MG, et al. Health effects of anticipation of job change and non-employment: longitudinal data from the Whitehall II study. BMJ 1995;311:1264-9.

30. Rognstad O, Steinset TA. Landbruket i Norge 2011 [Agriculture and forestry in Norway 2011]. Statistics Norway, 2012.

31. Mehta NK, House JS, Elliott MR. Dynamics of health behaviours and socioeconomic differences in mortality in the USA. J Epidemiol Community Health 2015;69:416-22.

32. Parent-Thirion A, Macías EF, Hurley J, et al. Fourth European working conditions survey. European foundation for the improvement of living and working conditions, 2007.

33. Booth NJ, Lloyd K. Stress in farmers. Int J Soc Psychiatry 2000;46:67-73.

34. Lazzarino Al, Hamer M, Stamatakis E, et al. The combined association of psychological distress and socioeconomic status with all-cause mortality: a national cohort study. JAMA Intern Med 2013;173:22-7.

35. Lazzarino Al, Hamer M, Stamatakis E, et al. Low socioeconomic status and psychological distress as synergistic predictors of mortality from stroke and coronary heart disease. Psychosom Med 2013;75:311-16.

36. Lett HS, Blumenthal JA, Babyak MA, et al. Depression as a risk factor for coronary artery disease: evidence, mechanisms, and treatment. Psychosom Med 2004;66:305-15.

37. Moustgaard H, Joutsenniemi K, Sihvo S, et al. Alcohol-related deaths and social factors in depression mortality: a register-based follow-up of depressed in-patients and antidepressant users in Finland. J Affect Disord 2013;148:278-85.

38. Kivimäki M, Gunnell D, Lawlor DA, et al. Social inequalities in antidepressant treatment and mortality: a longitudinal register study. Psychol Med 2007;37:373-82.

39. Leinonen $\mathrm{T}$, Martikainen $\mathrm{P}$, Laaksonen $\mathrm{M}$, et al. Excess mortality after disability retirement due to mental disorders: variations by socio-demographic factors and causes of death. Soc Psychiatry Psychiatr Epidemiol 2014;49:639-49.

40. Bjelland I, Lie SA, Dahl AA, et al. A dimensional versus a categorica approach to diagnosis: anxiety and depression in the HUNT 2 study. Int J Methods Psychiatr Res 2009;18:128-37. 